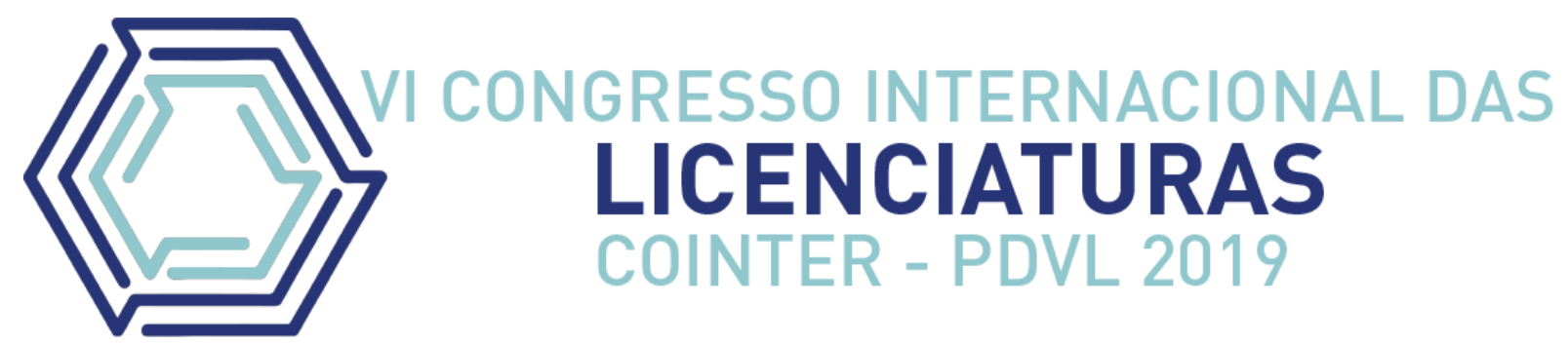

\title{
AS CONTRIBUIÇÕES DO CURSO DE LICENCIATURA EM PEDAGOGIA PARA A PRÁTICA PEDAGÓGICA NA EJA: UM ESTUDO COM OS EGRESSOS DA UFRPE/UAG
}

\section{LAS CONTRIBUCIONES DEL CURSO DE LICENCIA PEDAGÓGICA A LA PRÁCTICA PEDAGÓGICA EN EJA: UN ESTUDIO CON GRADUADOS EN UFRPE/UAG'S}

\section{THE CONTRIBUTIONS OF THE PEDAGOGY LICENSING COURSE TO PEDAGOGICAL PRACTICE IN EJA: A STUDY WITH UFRPE/UAG'S ALUMNI}

\author{
Apresentação: Comunicação Oral
}

Maria José Gomes Cavalcante ${ }^{1}$; Jeisy da Silva Melo ${ }^{2}$

\section{DOI: https://doi.org/10.31692/2358-9728.VICOINTERPDVL.2019.0106}

\section{Resumo}

No presente artigo apresentamos o resultado de um estudo realizado com egressos do curso de Licenciatura em Pedagogia da Universidade Federal Rural de Pernambuco - Unidade Acadêmica de Garanhuns (UAG), no qual tivemos como objetivo investigar se e como a formação inicial do curso de Licenciatura em Pedagogia da UFRPE/UAG contribuiu para a formação do educador da Educação de Jovens e Adultos (EJA). Participaram da investigação três professoras da rede municipal de ensino de Garanhuns/PE: uma atuava na Fase I e duas na Fase II. Realizamos uma pesquisa de campo (MARCONI \& LAKATO, 2009) com abordagem qualitativa (RICHADSON, 1999) e, para coleta dos dados, aplicamos uma entrevista semiestruturada (LUDKE \& ANDRÉ, 1996) com as participantes. Do ponto de vista teóricometodológico, respaldamo-nos na Constituição Federal (1988), Lei de Diretrizes e Bases da Educação Nacional (Lei 9394/96), Proposta Curricular Nacional do $1^{\circ}$ segmento para a Educação de Jovens Adultos (1997) e nas Diretrizes Curriculares Nacionais para o Curso de Licenciatura em Pedagogia, (2006), bem como trouxemos algumas considerações sobre a história da educação de jovens e adultos no Brasil e sobre a formação do educador de jovens e adultos, embasadas Arroyo (2006); Haddad e Di Pierro (2000); Pereira (2007); Cunha e Góes (1985); Oliveira (1999); Fonseca (2002); Freire (1996) e Soares (2006), dentre outros autores. De forma geral, os resultados deste estudo revelaram que o curso Licenciatura em Pedagogia da UFRPE/UAG tem contemplando a formação do educador em EJA, porém ainda não atende as necessidades de uma qualificação que podemos chamar de adequada, que discuta os diversos aspectos exigidos pelas especificidades desta modalidade de ensino.

Palavras-chave: Educação de Jovens e Adultos; formação inicial; educador da EJA

\footnotetext{
${ }^{1}$ Doutora em educação, UFRPE/UAG, mariajose.uag@gmail.com

${ }^{2}$ Graduanda em Licenciatura em Pedagogia, UFRPE/UAG, jeisymelo1@gmail.com
} 


\title{
Resumen
}

En el presente artículo presentamos el resultado de un estudio realizado con graduados del Grado de Pedagogía en la Universidad Federal Rural de Pernambuco - Unidad Académica de Garanhuns (UAG), en el cual buscamos investigar si y cómo la formación inicial del Grado en La pedagogía de la UFRPE/UAG contribuyó a la formación del educador de Educación de Jóvenes y Adultos (EJA). Tres profesores del sistema escolar municipal de Garanhuns/PE participaron en la investigación: uno actuó en la Fase I y dos en la Fase II. Realizamos una investigación de campo (MARCONI \& LAKATO, 2009) con un enfoque cualitativo (RICHADSON, 1999) y, para la recolección de datos, aplicamos una entrevista semiestructurada (LUDKE \& ANDRÉ, 1996) con los participantes. Desde un punto de vista teórico y metodológico, nos apoyamos en la Constitución Federal (1988), la Ley de Pautas y Bases de Educación Nacional (Ley 9394/96), la Propuesta de Currículo Nacional de 1er segmento para la Educación de Jóvenes Adultos (1997) y el Lineamientos Curriculares Nacionales para el Curso de Pedagogía (2006), así como algunas consideraciones sobre la historia de la educación de jóvenes y adultos en Brasil y sobre la formación del educador de jóvenes y adultos, con base en Arroyo (2006); Haddad y Di Pierro (2000); Pereira (2007); Cunha y Goes (1985); Oliveira (1999); Fonseca (2002); Freire (1996) y Soares (2006), entre otros autores. En general, los resultados de este estudio revelaron que el Grado en Pedagogía de la UFRPE/UAG ha contemplado la formación del educador en EJA, pero aún no satisface las necesidades de una calificación que podamos llamar adecuada, que discute los diversos aspectos requeridos por especificidades de esta modalidad de enseñanza.

Palabras clave: Educación de Jóvenes y Adultos; formación inicial; educador EJA.

\begin{abstract}
In the present article, we present the result of a study conducted with alumni of the Pedagogy Degree in the Federal Rural University of Pernambuco-Garanhuns Academic Unit (UAG), in which we aimed to investigate if and how the initial formation of the Degree in Pedagogy of the UFRPE/UAG contributed to the formation of the Educator of Youth and Adult Education (EJA). Three teachers from the municipal school system of Garanhuns/PE participated in the research: one worked in Phase I and two in Phase II. We conducted a field research (MARCONI \& LAKATO, 2009) with a qualitative approach (RICHADSON, 1999) and, for data collection, we applied a semi-structured interview (LUDKE \& ANDRÉ, 1996) with the participants. From a theoretical and methodological point of view, we endorsed the Federal Constitution (1988), the National Education Guidelines and Bases Law (Law 9394/96), the 1st segment National Curriculum Proposal for Young Adult Education (1997) and the National Curriculum Guidelines for the Pedagogy Degree Course (2006), as well as some considerations on the history of youth and adult education in Brazil and on the formation of the youth and adult educator, based Arroyo (2006); Haddad and Di Pierro (2000); Pereira (2007); Cunha and Goes (1985); Oliveira (1999); Fonseca (2002); Freire (1996) and Soares (2006), among other authors. In general, the results of this study revealed that the UFRPE/UAG Degree in Pedagogy has contemplated the formation of the educator in EJA, but still does not meet the needs of a qualification that we can call adequate, which discusses the various aspects required by specificities of this teaching modality.
\end{abstract}

Keywords: Youth and Adult Education; initial formation; EJA educator. 


\section{Introdução}

A Educação de Jovens e Adultos (EJA), de acordo com a Lei de Diretrizes e Bases da Educação Nacional (Lei nº 9394/96), é uma modalidade de ensino destinada aqueles indivíduos que não tiveram condições de acesso ou de continuidade de seus estudos no ensino fundamental e médio na idade própria. Ela contempla o Ensino Fundamental e Médio, considerados constitucionalmente como um direito, e objetiva contribuir para a formação de cidadãos conscientes de seus direitos e deveres na sociedade na qual se encontram inseridos.

A referida Lei afirma, inclusive, que as oportunidades educacionais a serem oferecidas aos estudantes da EJA, devem considerar as características deste alunado, seus interesses, condições de vida e de trabalho.

Partindo desta exigência, a formação do educador da EJA vem sendo discutida no cenário educacional nas últimas décadas, sobretudo a partir do reconhecimento da EJA como modalidade de ensino, do Parecer da Câmara de Educação Básica (CEB) no 11/2000, e da Resolução 01/2000, que trataram das Diretrizes Curriculares Nacionais para EJA.

É justamente nesse contexto de indagações sobre o perfil do educador da EJA (ARROYO, 2006), sobre a(s) metodologia(s) utilizada(s) na formação desse educador nas instituições de educação superior que se originou essa pesquisa. Inquietou-nos, assim, saber como o curso de Licenciatura em Pedagogia vem formando professores para atuarem nessa modalidade de ensino, buscando responder as seguintes questões: o curso de Licenciatura em Pedagogia tem contribuído para atuação do (futuro) professor na EJA? Quais são essas contribuições? E, ainda, quais são lacunas desta formação inicial?

Tivemos, para tal, como objetivo geral: investigar se e como a formação inicial do curso de Licenciatura em Pedagogia da UFRPE/UAG contribuiu para a formação do educador da Educação de Jovens e Adultos (EJA).

Participaram da investigação três professoras da rede municipal de ensino de Garanhuns/PE. Realizamos uma pesquisa de campo (MARCONI \& LAKATO, 2009) com abordagem qualitativa (RICHADSON, 1999) e, para coleta dos dados, aplicamos uma entrevista semiestruturada (LUDKE \& ANDRÉ, 1996) com as participantes.

Contextualizando a educação de jovens e adultos no Brasil: uma breve retrospectiva na história 
No Brasil, a prática educativa desenvolvida com jovens e adultos acontece desde o período colonial, os religiosos exerciam suas ações educativas religiosas em grande parte com adultos. Inicialmente com os indígenas, posteriormente, com escravos e mais tarde eles se encarregaram das escolas de humanidades para os colonos e seus filhos (HADDAD \& DI PIERRO, 2000). Assim podemos observar que havia a preocupação em catequizar adultos e jovens, tanto nativos, quanto colonos, diferenciando apenas os objetivos para cada grupo social, bem como que a ação alfabetizadora tinha como objetivo de difundir o evangelho, como também de transmitir normas de comportamento.

Esta organização da educação perdurou até 1759, pois com a expulsão dos jesuítas, gerou-se uma desorganização no ensino, vindo após a Reforma Pombalina (ROMANELLI, 1998). As aulas régias implementadas pela reforma compreendiam o estudo das humanidades, sendo pertencentes ao Estado - foi a primeira forma do sistema de ensino público no Brasil. Apesar da novidade imposta, na prática o sistema das aulas régias pouco alterou a realidade educacional no Brasil, tampouco se constituiu numa oferta de educação popular, ficando restrita às elites locais.

Passado este período, segundo Haddad e Di Pierro (2000), só encontraremos alguma informação sobre a educação de jovens e adultos no período imperial, instaurado no Brasil a partir de 1822. Neste novo contexto político, originou-se a primeira constituição brasileira, que dentro do campo dos direitos legais, afirmava a garantia de uma "instrução primária e gratuita para todos os cidadãos", incluindo assim a população jovem e adulta. Mas o direito que nasceu com a norma constitucional não passou da intenção legal.

A partir de 1930, a educação básica começou delimitar seu lugar na história do país, com a consolidação um sistema público elementar. Neste período, o fato da sociedade brasileira está passando por grandes transformações, associado ao processo industrial e também a concentração populacional nos centros urbanos, gerou crescimento e levou o Governo Federal a traçar diretrizes educacionais para todo o país com objetivo de delegar responsabilidade aos estados e municípios. Com isso, especialmente em 1940, o ensino elementar foi ampliado também para os adultos.

Com o fim da ditadura Vargas e o recente fim da Segunda Guerra Mundial (1945), o país vivia o fervor da política de redemocratização. Tais fatos contribuíram para que a educação de adultos ganhasse mais destaque em meio à propagação da educação básica, bem como a urgência em aumentar o eleitorado para a manutenção do governo central (PEREIRA, 2007). 
Com tal objetivo, implementou-se a I Campanha de Educação de Jovens e Adultos no Brasil. Não havia nenhuma exigência de formação ou preocupação em formar adequadamente os professores para o ensino de jovens e adultos. Ensinar mulheres e homens analfabetos constituía uma ação filantrópica. Neste período, as aulas para os adultos aconteciam à noite, com professores voluntários, utilizando recursos apropriados ao ensino de crianças.

Segundo Soares (2006) ainda neste ano, aconteceu o I Congresso Nacional de Educação de Adultos, no qual já se ressaltava a questão de uma formação adequada do professor para trabalhar na alfabetização de jovens e adultos.

Em 1950, o clima de entusiasmo começou a diminuir devido à falta de empenho dos governantes. A Campanha, que inicialmente obtivera significativos resultados, não obteve o mesmo sucesso nas ações realizadas no espaço rural, bem como as críticas à mesma denunciavam a superficialidade do aprendizado que se efetivava e a inadequação do método utilizado para a população adulta. Desta forma, sobreviveu somente a rede de ensino supletivo.

Todas essas questões colaboraram para um repensar direto sobre as práticas pedagógicas que estavam sendo vivenciada na educação de jovens e adultos, como também a ausência de uma formação específica para o professorado. Discussões essas que foram levantadas no II Congresso Nacional de Educação de Adultos, em 1958.

[...] marcava o Congresso o início de um novo período na educação de adultos no Brasil, aquele que se caracterizou pela intensa busca de maior eficiência metodológica e por inovações importantes nesse terreno, pela reintrodução da reflexão sobre o pensamento pedagógico brasileiro e pelos esforços realizados pelos mais diversos grupos em favor da educação população adulta para a participação na vida política da nação. (PAIVA, 1973, p. 210)

Pereira (2007) ratifica ainda que nesse evento a preocupação dos educadores não se restringia com os métodos eficazes, mas também com as consequências sociais, políticas e sociais de seus trabalhos.

No ano de 1960 surge, então, uma nova visão sobre o analfabetismo e consolida-se um novo paradigma pedagógico para educação de adultos, cuja referência foi o educador Paulo Freire. Assim, a partir do seu pensamento e a sua proposta inspiraram os Movimentos de Cultura e Educação Popular com método adequado para a população jovem e adulta nas diferentes regiões do país.

Com o golpe militar ocorrido neste mesmo ano, os Movimentos passaram a ser vistos como ameaças à ordem e foram extintos, em sua maioria. O governo, então, assumiu o controle dessa atividade e criou o Movimento Brasileiro de Alfabetização (MOBRAL). 
O MOBRAL surge com força, mas sem a preocupação com o fazer e o saber docente, pois qualquer pessoa que soubesse ler e escrever também podia ensinar. As orientações metodológicas e produção de materiais didáticos eram centralizadas, vazio de todo sentido crítico.

A mudança no cenário político, a promulgação da nova Constituição Federal (1988) trouxe algumas conquistas aos trabalhadores, entre elas, a gratuidade e a obrigatoriedade do ensino fundamental para todos (PEREIRA, 2007). A Educação de Jovens e Adultos tornou-se modalidade da educação básica com a aprovação da Lei de Diretrizes e Bases da Educação Nacional (LDBEN), Lei $n^{\circ}$ 9.394/96, que legislou sobre a necessidade da formação específica para o educador da referida modalidade.

\section{A formação do educador da EJA: o que comtemplar?}

Como apresentado na retrospectiva sobre a Educação de Jovens e Adultos, podemos observar que a preocupação em relação à formação do educador da EJA vem se mostrando cada vez mais presente nas discussões atuais sobre esta modalidade e suas especificidades

Dentro do que propõe as medidas legais, alguns documentos asseguram aos jovens e adultos a educação escolar, bem como explicitam a necessidade de uma formação mais especifica para educador da EJA. Nessa perspectiva destacamos a Constituição da República Federativa do Brasil (1988), Capitulo II, Artigo $6^{\circ}$, que ao tratar da educação considera que: "são direitos sociais, a educação, a saúde, a alimentação, o trabalho, a moradia, o lazer, a segurança, a previdência social, a proteção a maternidade e a infância, a assistência social aos desamparados, na forma desta Constituição".

De acordo com o artigo apresentado, a educação se constitui um direito social e, portanto, direito de todo cidadão, inclusive de jovens e adultos que foram excluídos do sistema escolar e hoje buscam por meio da educação melhoria para sua condição social.

Em consonância com a afirmação constitucional, a LDBEN (nº 9.394/96), em seu Artigo 37 , Inciso $1^{\circ}$, assegura o direito à educação ao público jovem e adulto e faz algumas considerações em relação às oportunidades educacionais que devem ser garantidas ao mesmo. Ela afirma que:

Art.37. A educação de jovens e Adultos será destinada àqueles que não tiveram acesso ou continuidade de estudos no ensino fundamental e médio na idade própria. ${ }^{\S}$ $1^{\circ}$ Os sistemas de ensino assegurarão gratuitamente aos jovens e aos adultos, que não puderam efetuar os estudos na idade regular, oportunidades educacionais apropriadas consideradas as características do alunado, seus interesses, 
condições de vida e de trabalho, mediante cursos e exames. (grifo nosso)

$\mathrm{O}$ artigo apresentado nos remete à necessidade de um contexto escolar que favoreça a uma prática pedagógica direcionada às características dos estudantes. Assim sendo, torna-se também necessário que o (futuro) educador desta modalidade tenha uma formação que contemple as especificidades da mesma, já que diferentemente de ensinar crianças, ensinar jovens e adultos requer conhecimentos relativos a estas fases da vida, no que diz respeito aos aspectos psicológicos, cognitivos, dentre outros.

Em relação à formação do profissional da educação no Brasil, o artigo 61 da LBDEN explicita, em seu caput, que os objetivos que devem norteá-la são: o atendimento adequado aos diferentes níveis de modalidades de ensino e as características de cada fase do desenvolvimento do educando.

Tratando sobre esta temática, as Diretrizes Curriculares Nacionais para Educação de Jovens e Adultos estabelecem, no item VIII, que

\footnotetext{
(...) o preparo de um docente voltado para a EJA deve incluir, além das exigências formativas para todo e qualquer professor, aquelas relativas à complexidade diferencial desta modalidade de ensino. Assim, esse profissional do magistério deve estar preparado para interagir empaticamente com esta parcela de estudante e de estabelecer o exercício do diálogo. (BRASIL, 2000, p.56)
}

Fica evidente que a formação do educador de EJA deve contribuir de forma significativa para uma prática respeitosa, devendo oportunizar a este profissional subsídios necessários para que seja capaz de compreender a realidade do educando, sua identidade cultural e assim adotar uma postura democrática diante do saber socialmente construído, admitindo o diálogo igualitário entre os saberes do educando e os saberes escolares. Fica, também, evidente o reconhecimento da necessidade da formação específica do educador de jovens e adultos. Neste sentindo, indagamos: quais aspectos devem ser considerados nesta formação?

Discutindo sobre a formação do educador da EJA, Arroyo (2006) afirma que o perfil do educador de jovens e adultos e sua formação estão em construção e apresenta alguns aspectos devem ser considerados neste processo, levando em conta que "a Educação de Jovens e Adultos sempre fez parte da dinâmica da sociedade, da dinâmica mais emancipadora" (p.19), ou seja, está no contexto dos que lutam pelos direitos da classe popular e nunca relacionada exclusivamente ao governo ou ao sistema educacional. Acreditamos que, para se manter essa dinâmica emancipatória que foi conquistado ao longo da história, se faz necessário que os cursos para os educadores desta modalidade incorporar na sua formação o perfil de educador plural, bem mais que o educador da escola formal. Este educador plural possui traços ricos de 
educador múltiplo, que é um militante e sua pratica vai além de ensinar a ler e escrever do somente alfabetizar, a sua ação educativa oferece uma libertação maior do que o educador da escola formal, ou seja, possibilita uma maior reflexão sobre si e sobre o meio em que está inserido.

O autor supracitado considera, ainda, que “(...) um dos traços da formação dos educadores de Jovens e Adultos tem de ser conhecer as especificidades do que é ser jovem, do que é ser adulto" (2006, p.28). Nesse sentido, sabemos que o jovem e adulto, estudante da EJA, possuem necessidades e expectativas próprias e que tem trajetória de vida social, ético e racial diferenciada de outros jovens e adultos. Segundo, Oliveira (1999), esse adulto não é profissional qualificado ou estudante universitário, geralmente, ele é um migrante da zona rural, com passagem curta pela escola, filho de analfabetos, com experiência de trabalho rural na infância e na adolescência, que busca a escola para alfabetizar-se. O jovem é em geral também um excluído da escola, incorporado aos cursos supletivos de classes mais adiantadas, com maiores chances de concluir o ensino fundamental e médio. Sendo assim um público com características específicas que precisam ser consideradas no seu processo de ensino.

Alguns autores (OLIVEIRA, 1999; FONSECA, 2002) estudiosos da educação de jovens e adultos, afirmam que para compreender as especificidades dos jovens e adultos estudantes da EJA, bem como contribuir no seu processo de aprendizagem, faz-se necessário que o educador de EJA reflita sobre três campos específicos: a condição de não criança, a condição de excluídos da escola e condição de membros de determinados grupos culturais.

Logo se faz necessário que o (futuro) educador de EJA compreenda, na sua formação, que ele precisa ter o conhecimento de quem são esses jovens e adultos, como constroem a sua história, como aprendem, bem como que a complexidade em ser professor nessa modalidade de ensino requer um olhar especial para com esses alunos e a promoção da aprendizagem, respeitando suas especificidades.

Além dos aspectos acima apresentados, Arroyo (2006, p. 28) acrescenta que “(...) quem vai trabalhar com a EJA deve ter uma fundamentação sólida sobre a história dos direitos humanos" e nesta discussão, destacar a luta pela conquista a educação vinculado aos outros direitos. Uma vez que o jovem e adulto faz um grande esforço para voltar à escola, para garantir o acesso à educação, ao trabalho, a cidadania e a inclusão social. Em suma, a EJA nunca aparece como direito isolado sempre vem acompanhado de lutas por outros direitos. 
Vinculada ao resgate do direito à educação, Arroyo propõe o estudo dos movimentos de educação popular dos anos de 1960, uma vez que prática educativa vivenciada nestes estava relacionada às demandas sociais do grupo, resgate dos direitos negados e a transformação social.

Diante disso, percebemos que a formação inicial para esse profissional que pretende atuar nesta modalidade de ensino, deve contemplar toda a trajetória da própria história da Educação de Jovens Adultos, recuperando assim, o perfil de fazer parte da dinâmica emancipadora da sociedade e desenvolver as competências necessárias para sua prática, de acordo com o momento vivido pelo jovem e adulto.

\section{Metodologia}

Para a concretização deste estudo, realizamos uma pesquisa de campo com abordagem qualitativa. Optamos por tais abordagens em função do objetivo proposto.

Segundo Richadson, (1999) a uma metodologia qualitativa pode descrever a complexidade de determinado problema, analisar a interação de certas variáveis, compreender e classificar processos dinâmicos vividos por grupos sociais. Ainda, de acordo Oliveira (2005), esta abordagem pode ser caracterizada como sendo um estudo detalhado de um determinado fato, objeto, grupo de pessoas ou ato social e fenômeno da realidade e, ainda acrescenta que se caracteriza por responder questões bastante particulares, uma vez que se preocupa um nível de realidade que não pode ser quantificados. A pesquisa de campo por sua vez "consiste na fatos e fenômenos tal como ocorrem espontaneamente na coleta de dados a eles referentes e no registro de variáveis que se presumem relevantes (...)" (MARCONI \& LAKATOS, 2009, p.188). Realizamos também uma pesquisa bibliográfica sobre tema, como a primeira fase da pesquisa de campo, com objetivo de fazer um levantamento dos referenciais teóricos necessários a análise proposta.

Em relação aos procedimentos metodológicos, realizamos com as três participantes uma entrevista semiestruturada, pois esse tipo instrumento permite penetrar mais profundamente na complexidade de um problema (RICHARDSON, 1999). A entrevista estava estruturada em dois blocos: (1) questões sobre o curso de Licenciatura em Pedagogia realizado pela participante; (2) questões sobre a experiência da participante como educadora da EJA.

Como já exposto, contamos com a participação de três educadoras que se encontram em exercício na Educação de Jovens e adultos das fases I e II. Os critérios de escolha das mesmas 
forma: (1) ter cursado Licenciatura em Pedagogia na UFRPE/UAG; (2) estar atuando em turmas da EJA; (3) ter disponibilidade em participar da pesquisa. No Quadro 1, a seguir, apresentamos a caracterização das professoras:

Quadro 1: caracterização das professoras

\begin{tabular}{|c|c|c|c|c|}
\hline Participantes & $\begin{array}{l}\text { Ano de ingresso e } \\
\text { conclusão do curso de } \\
\text { Lic. Pedagogia } \\
\text { UAG/URPE }\end{array}$ & $\begin{array}{l}\text { Tempo } \\
\text { docência }\end{array}$ & $\begin{array}{l}\text { Tempo de docência } \\
\text { na EJA }\end{array}$ & $\begin{array}{l}\text { Fase } \\
\text { leciona }\end{array}$ \\
\hline Professora 1 & $2010-2013$ & 06 anos & 06 anos & I \\
\hline Professora 2 & $2011-2014$ & 17 anos & 17 anos & II \\
\hline Professora 3 & $2011-2014$ & 09 anos & 08 anos & II \\
\hline
\end{tabular}

Como observamos no Quadro, todas professoras já lecionavam antes de mesmo de fazer o curso de Licenciatura em Pedagogia por serem formadas em Magistério ou Normal Médio e já possuíam grande experiência de ensino na EJA. Elas lecionavam em turmas do $1^{\circ}$ Segmento (Fase I e II) em duas escolas da rede municipal de ensino de Garanhuns/PE.

\section{Resultados e Discussão}

Nesta seção, procederemos à análise e reflexão dos discursos das participantes organizadas em 3 categorias delimitadas a partir das respostas das docentes em relação ao curso de Licenciatura em Pedagogia e a experiencia com educadoras da EJA.

(1) A opção das professoras pelo curso de Licenciatura em Pedagogia e as suas contribuições para a sua formação profissional

Nesta categoria, apresentamos os depoimentos das participantes sobre os motivos da escolha e da identificação com o curso de Pedagogia, a avaliação que as elas fizeram do mesmo, apresentando seus aspectos relevantes para a formação profissional e suas lacunas diagnosticadas.

Em relação à opção pelo curso, as professoras afirmaram que a escolha estava pautada no desejo/necessidades que sentiam de se aperfeiçoar na área que já atuavam, pois elas já tinham cursado o Magistério ou Normal Médio. A principal expectativa era que a Licenciatura em Pedagogia pudesse lhes fornecer os subsídios teórico-práticos necessários à formação do educador e sua prática na sala de aula e justificaram, ainda, a escolha por pensarem ser esta a 
graduação (entre as demais), que lhes proporcionaria mais adequadamente a formação necessária. Isto ficou evidente em suas falas. "Optei fazer o curso de Pedagogia porque tinha cursado magistério e sentia que
não podia ficar somente com o nível médio, era uma necessidade minha, pois passei
em um concurso municipal na área da educação e queria uma formação que pudesse
contribuir com o meu trabalho.[... pensei que o curso de Pedagogia podia me
oferecer teorias e práticas que viessem contribuir para o meu trabalho. Como de
fato contribuiu." (Professora 1)

"Optei por esse curso porque eu já tinha o magistério e era uma forma de me aprimorar, me aperfeiçoar por conta do meu trabalho e ter um conhecimento mais aprofundado. Eu tinha outro curso, mas não era na área de educação e eu achei relevante ter uma formação acadêmica em um curso que estava dentro do meu diaa-dia que era sala de aula." (Professora 2)

"Eu tinha cursado Normal Médio, e para um maior aperfeiçoamento como professora, fiz a opção por Pedagogia, pois acredito que nenhum outro curso dá o mesmo suporte para trabalhar com o ensino fundamental como a Pedagogia. As outras licenciaturas são mais voltadas para turmas a partir do $6^{\circ}$ ano" (Professora 3)

Como podemos perceber nas falas das professoras, o motivo pelo qual as levou a fazer a opção pelo curso de Pedagogia se caracteriza na buscar de identificar na sua formação a relação entre teoria e a prática. Nessa perspectiva as Diretrizes Curriculares Nacionais para o Curso de Graduação em Pedagogia (2006), em seu artigo 3º, afirmam que

O estudante de Pedagogia trabalhará com um repertório de informações e habilidades composto por pluralidade de conhecimentos teóricos e práticos, cuja consolidação será proporcionada no exercício da profissão, fundamentando-se em Princípios de interdisciplinaridade, contextualização, democratização, pertinência e relevância social, ética e sensibilidade afetiva e estética.

Assim, as Diretrizes propõem que o curso deve oportunizar ao graduando a discussão sobre os saberes teóricos e práticos, para que estes se constituam uma base (sólida) para sua prática educativa.

Ainda com relação curso de pedagogia, foi interessante observarmos que todas as docentes investigadas afirmaram sua identificação com o mesmo e justificaram-na apontando os motivos. Segundo as professoras, de forma geral, o curso correspondeu às expectativas e as necessidades, que as levaram a optar por ele, ao oportunizar o aprofundamento de seus conhecimentos sobre o desenvolvimento das crianças, as teorias da aprendizagem, o processo de aquisição da leitura e escrita, bem como a relação destes com a prática docente. Além disto, foi colocado pelas participantes que os seminários, as trocas de experiências com os colegas, as discussões, as aulas extraclasse vivenciadas durante o curso contribuíram para a identificação com o mesmo. 
Ressaltamos os aspectos positivos elencados pelas participantes predominantemente estavam relacionados ao ensino, à aprendizagem e ao desenvolvimento da criança, provocandonos algumas indagações: o curso de Licenciatura em Pedagogia tem privilegiado ou mesmo se limitado ao estudo dos conteúdos e conceitos sobre a infância e seu processo de ensino e aprendizagem? Que estudos e discussões estão sendo vivenciados em relação aos estudantes jovens e adultos e seu processo de ensino e aprendizagem? Não temos, entretanto, aqui a intenção de responder tais questões, mas de provocar uma reflexão a partir das respostas das entrevistas.

Dando continuidade, solicitamos às professoras que apontassem conteúdos ou temáticas que não foram abordadas ou trabalhadas suficientemente no curso. Nos depoimentos das professoras 1 e 3 , podemos perceber que ambas apontaram o tempo disponível para o trabalho com determinadas disciplinas (LIBRAS e Estágio Supervisionado) foi insuficiente para garantir uma discussão mais aprofundada dos assuntos abordados, a professora 2 indicou a falta de comprometimento por parte dos professores de algumas disciplinas

\footnotetext{
"Uma das lacunas do curso foi a pouca discussão sobre inclusão social, foi visto foi de forma muito rápida. Quando me refiro à inclusão social é no sentido, das diversas deficiências que existe e não temos tempo de nos aprofundar, por exemplo, vimos assunto sobre a disciplina de LIBRAS e pouco sobre braile e nós precisávamos ver mais de forma prática. (Professora 1)

“[...] algumas disciplinas o professor não tinha comprometimento... [...] como lacuna nas disciplinas de Matemática e também Didática, deixaram a desejar." (Professora 2)

“Como lacuna, posso apontar as aulas de LIBRAS que aconteceram somente em um período, as disciplinas de estágio que deviam acontecer já desde o início do curso. A disciplina de coordenação que só apareceu no final do curso. Também considero negativas as disciplinas optativas, não tem o que optar em nosso horário de aula, são aquelas, uma em cada período e não há o que escolher. A disciplina da EJA tem apenas em um período e tem muita coisa importante que não dar tempo de ver." (Professora 3)
}

De modo geral, as entrevistadas evidenciam que durante o curso algumas temáticas não foram vistas ou abordadas com aprofundamento. Entre as respostas dadas, destacamos a fala da professora 3, que afirma que a disciplina Educação de Jovens e Adultos é ministrada apenas em um único período. Em consonância com este depoimento, Arroyo (2006) afirma que nos cursos Licenciatura em Pedagogia tem-se mais carga horária para discutir e estudar conteúdos, métodos, gestão, supervisão do que para discutir e estudar a história e vivências concretas da infância e da adolescência e que "em relação a história e as vivências concretas de jovens e adultos populares trabalhadores, as lacunas são ainda maiores" (p.22). 
Sobre a mesma temática, Freire (1996), colaborando na discussão, defende que o professor só pode ensinar se estiver habilitado para trabalhar com seus educandos (sejam eles; crianças, jovens, adultos, idosos) e seguro dos conteúdos da sua disciplina. Isto, porém, nem sempre acontece, pois, uma formação generalista não consegue desenvolver competências necessárias para que o educador ensine nos níveis e modalidades, visto que estes estão direcionados aos diferentes públicos.

\title{
(2) A disciplina Educação de Jovens e Adultos no curso de Licenciatura em Pedagogia:
} conteúdos e temáticas abordadas e suas relações com as demais disciplinas do curso. Durante as entrevistas, as três docentes investigadas afirmaram que a disciplina de EJA era obrigatória e constituía-se como um dos requisitos para a conclusão do curso de Licenciatura em Pedagogia.

Quando indagadas acerca dos conteúdos e temáticas abordadas na disciplina de Educação de Jovens e Adultos, as três participantes elencaram algumas delas, que tiveram maior relevância para a sua prática, como podemos ver nos extratos de suas entrevistas, a seguir:

\begin{abstract}
"Na disciplina de EJA, o que consigo lembrar foi que estudei sobre a história da EJA, sobre o Mobral e a revolução que Paulo Freire provocou na educação. Fiz também um resumo de um livro que tinha como tema "Ato de ler" todas essas abordagens foram muito boas.. Outra questão também que foi discutido era como ensinar os conteúdos sem infantilizar o jovem e adulto, selecionando assuntos adequados com a realidade da turma, considerando as suas especificidades Por exemplo, com a minha turma eu falo sobre questões sociais, eu posso falar sobre esgoto que faz parte do seu dia a dia e esse assunto pode ser discutido durante uma semana, e, eu posso até alfabetizar com esse assunto. Por isso considero muito bom, o que foi visto, pude colocar em prática." (Professora 1)
\end{abstract}

"Nas aulas foi discutido que a EJA, sempre foi à margem, tem uma história de negação, nunca foi dado o mesmo valor como o ensino fundamental. Durante a disciplina, nós também tivemos uma viagem para o Centro Paulo Freire na Federal, onde lá assistimos a uma palestra de Agostinho Rosa que fez doutorado com o tema "Paulo Freire". Esse momento abriu minha cabeça de forma que passei a ver a EJA de maneira diferente, ofereceu subsídios para uma reflexão sobre EJA, aprimorando meus conhecimentos com a troca de experiência em sala relacionando teoria e prática e experiência que os colegas também tinham. Foi discutido que os livros didáticos que eram voltados para as crianças se tornam inadequados para os jovens e adultos, e com isso os conteúdos infantilizam. Também discutíamos como trabalhar com os jovens e adultos partindo sempre da sua realidade tornando assim o que estava sendo discutido interessante para sua vida. Tudo isso, contribui para minha prática, uma vez que tive oportunidade de discutir sobre essas questões. "(Professora 2)

"Lembro de algumas discussões levantadas em sala, como por exemplo, eu não posso dar aula da mesma maneira que dou para criança por que preciso considerar a história de vida do jovem e adulto, a sua realidade, também em 
leituras realizadas em livros de Freire, assim, ficou bem marcado pra mim, que ninguém nunca sabe tudo, cada um tem seu saber e que, independente da idade, precisamos valorizar o saber do outro e a sua capacidade. E a cada dia aprendemos e ensinamos. E, tudo que foi visto, foi e está sendo subsídios para minha atuação em sala de aula." (Professora 3)

De acordo com os relatos, a disciplina Educação de Jovens e Adultos trouxe contribuições para sua prática como educadoras desta modalidade, ao oportunizar o estudo e discussão sobre a história da educação de jovens e adultos, a concepção Freiriana de educação, as especificidades dos estudantes da EJA. Segundo as docentes foi enfatizado o respeito pelo saber dos educados e os seus interesses; a necessidade da contextualização dos conteúdos trabalhados, levando em conta a realidade da turma; bem como se discutiu a não infantilização da prática pedagógica, ou seja, a necessidade de uma metodologia apropriada aos estudantes da EJA. Diante do que foi apresentado, percebemos que a formação profissional das educadoras, teve um valor significativo para seu fazer docente, pois favoreceu para compreender algumas situações encontradas no seu trabalho.

Em relação, ainda, à disciplina Educação de Jovens e Adultos, as professoras foram questionadas se a discussão realizada na mesma foi suficiente para sua formação e atuação na EJA. De forma geral, as educadoras consideraram insuficiente a discussão e justificaram suas respostas em função da carga horária de apenas 45 horas/aula da disciplina e por ser única

As respostas dadas, mais uma vez, vêm a confirmar o que os teóricos (ARROYO, 2006; SOARES, 2006; FONSECA, 2002; dentre outros) defendem a necessidade de uma discussão mais específica e mais aprofundada sobre a educação do público da EJA na Licenciatura em Pedagogia.

Indagadas sobre outras disciplinas no curso de Pedagogia que estavam relacionadas à educação de pessoas jovens e adultas, cada professora indicou disciplinas diferentes, entre elas: Fundamentos Sócio-Filosóficos e Históricos da Educação., Políticas Públicas em Educação, Identidade e alguma disciplinas metodológicas.

De forma geral, as entrevistadas confirmaram nos seus relatos que a disciplina Educação Jovens e adultos possibilitou reflexões acerca dos jovens e adultos e sobre a prática pedagógica nesta modalidade, e ainda outras disciplinas trouxeram, de forma indireta, algumas contribuições. Porém, tais discussões deixaram lacunas ao serem consideradas insuficientes pelas professoras para que desenvolvessem uma prática apropriada ao público da EJA.

Nesta direção, Arroyo (2006) apresenta alguns aspectos necessários à formação do profissional, que pretende atuar na Educação de Jovens Adultos, defendendo que o educador 
precisa tomar consciência da trajetória histórica desta modalidade, recuperando assim o perfil militante deste educador e desenvolver uma prática de acordo com o contexto vivido atualmente, dentre outros. Para contemplar tais aspectos, como a afirmam as participantes, uma só disciplina em um só semestre bem como discussões esporádicas em outras disciplinas não constituiu uma base para ação pedagógica na EJA.

\section{(3) As contribuições do curso de Licenciatura Pedagogia para a prática pedagógica} das professoras.

Em seus depoimentos, todas as docentes investigadas revelaram que se apoiavam nas ideias de Paulo Freire para pensar a sua prática na sala de aula. Em suas palavras:

\footnotetext{
"As ideias de Paulo Freire em considerar o contexto do jovem adulto, o que me leva trabalhar em sala também músicas de MPB. Por exemplo, trabalhar de acordo com o seu cotidiano, usar uma palavra geradora, também trabalhar de forma interdisciplinar, como nas disciplinas de português, matemática, geografia, história, enfim englobar todas as disciplinas em um mesmo assunto abordado." (Professora 1)

"Uso como referência as Diretrizes Curriculares para a EJA, orientações que recebemos nas formações continuadas e procuro sempre trabalhar de acordo com as necessidades que eles demonstram ter, levando em conta o que diz Paulo Freire em relação à paciência, respeito, que todos aprendem juntos com a troca de experiência. Uso algumas das suas pedagogias, mas não sou fã de Freire, acho muito repetitivo e com uma linguagem difícil." (Professora 2)

"Paulo Freire. Principalmente a questão do respeito ao conhecimento que os alunos da EJA já possuem. Trabalhar a autoestima para que eles se sintam valorizados. Também Arroyo quando fala sobre considerar as especificidades da EJA. Então é isso, tudo que estudei procuro colocar em prática." (Professora 3)
}

Os depoimentos das educadoras nos remetem o que falava Freire ao longo da sua história como educador e que teve uma repercussão significativa na educação de jovens e adultos, desde o início dos anos 60 (BRASIL, 1997), e até os dias de hoje seu pensamento contribui para a prática docente de muitos profissionais.

As professoras destacam Freire quando se refere à paciência, ao respeito, ao aprendizado que se constrói com a troca de experiência, ao considerar o cotidiano do educando, ao uso de palavra geradora, ao trabalhar a interdisciplinaridade, humanização, politização, respeito ao conhecimento que os educandos já trazem das suas vivências. Além das contribuições das ideias desse teórico, as docentes também citaram outros estudiosos cujos pensamentos têm relação direta com as especificidades dessa modalidade de ensino, bem como a Proposta Curricular 
destinada a esse segmento. É interessante observamos que, em se tratando do que é feito na sala de aula, os professores recorrem a vários caminhos teórico-metodológico para dar conta da complexidade que é o ato de ensinar.

Em relação às contribuições que o curso de Licenciatura em Pedagogia proporcionou para a sua formação enquanto educador de EJA, as docentes expuseram em seus relatos:

\begin{abstract}
"O curso de Pedagogia ajudou bastante no sentido de como lidar com essa turma, pois têm suas especificidades, a metodologia é diferente de como se trabalha com crianças. Por exemplo, pela manhã eu uso uma música infantil com uma turma formada por crianças, à noite utilizo um poema que tem haver com a turma da EJA. Não que eu não possa trabalhar com a criança um poema, mas é um poema diferente de acordo com sua faixa etária e, é com outro direcionamento. As abordagens devem ser apropriadas para cada público, ou seja, que tenha haver com o seu contexto." (Professora 1)

"O curso ofereceu subsidios para uma reflexão sobre essa modalidade, trouxe alguns conhecimentos, aprimorados através da troca de experiência com os colegas em relação à prática, considero que foi muito proveitoso." (Professora 2)

"Contribuiu orientando como se deve trabalhar com a EJA. Assim procurar atender o que é do interesse da turma ou que tenha significado para eles." (Professora 3)
\end{abstract}

Como podemos perceber nas colocações das professoras, de modo geral suas formações contribuíram de alguma forma para as suas práticas pedagógicas em turmas de Educação de Jovens e adultos. Uma vez, que passaram a refletir sobre questões que anteriormente não tinha conhecimento. Desse modo, fica evidente que a graduação, mesmo não discutido todos os assuntos necessários à formação do educador da EJA, possibilitou um olhar mais cuidadoso, e de alguma forma, um despertar para uma nova visão quando se trata desta modalidade de ensino.

\title{
Conclusões
}

Nesse estudo, como explicitado, entrevistamos três professoras que lecionam em turmas da EJA, a fim de identificar na formação inicial aspectos que favorecem para a qualificação e fazer docente.

A exploração dos dados nos ofereceu condições de constatar algumas das hipóteses traçadas, ao iniciarmos esta pesquisa, relacionadas às possíveis concepções que estejam se configurando para os educadores da EJA, como que a de perceber que os estudantes desta modalidade de ensino como um público que possui necessidades e características próprias, com 
seu tempo mental, social e cultural, bem como a consciência da trajetória, dos vínculos entre EJA e luta pelos direitos humanos

No que dizem respeito às entrevistas realizadas com as professoras, as mesmas demonstraram que de alguma forma a Licenciatura em Pedagogia contribuiu para sua formação e pratica em turmas da EJA. Destacando que, mesmo as discussões não sendo suficientes para discutir de forma aprofundada sobre questões pertinentes a este público, mas gerou uma inquietação para buscar mais informação, despertado assim, a partir dos momentos vividos na graduação, como as viagens pedagógicas, seminários e conversas em salas de aula que discutiam sobre questões referentes esta modalidade de ensino o que levou principalmente a perceber que este público possui características próprias, nos relatando que é imprescindível ao educador desta modalidade à busca de novos conhecimentos, para com isso, desenvolver em sala de aula uma ação pedagógica condizente com as especificidades do jovem e adulto.

No que se refere à prática, as professoras relataram que em suas aulas buscam contemplar o que tem significado para seus alunos e que também é necessário considerar sempre o contexto social do educando e o saber que estes já construíram em seu cotidiano.

Sabemos que o educador com uma boa formação pode em seu trabalho pedagógico desenvolver na sala de aula interação social favorável à construção de novos saberes e à troca de experiências, contribuindo assim para o crescimento educacional coletivo e individual. Portanto finalizamos dizendo que, a formação do educador deve favorecer para uma ação pedagógica eficiente e eficaz, através da promoção de situações que favoreçam o desenvolvimento da sociabilidade, da cooperação e do respeito mútuo entre os estudantes, desse modo, ter acesso a uma aprendizagem significativa para seu convívio social.

\section{Referências}

ARROYO, Miguel. Formar educadores e educadoras de jovens e adultos. In: SOARES, Leôncio. (org.) Formação de educadores de jovens e adultos. Belo Horizonte: Autêntica, 2006.

BRASIL. Constituição (1988). Constituição da República Federativa do Brasil: promulgada em 5 de outubro de 1988. 4. ed. São Paulo: Saraiva, 1990.

BRASIL, Congresso Nacional. Lei de Diretrizes e Bases da Educação Nacional (Lei Federal $n^{0}$ 9394). 
BRASIL, Ministério da Educação e do Desporto e Ação Educativa Educação de Jovens e Adultos: Proposta curricular - $\mathbf{1}^{\mathbf{o}}$ segmento do Ensino Fundamental/

Brasília: MEC, SEF: Ação Educativa, 1997.

BRASIL. Ministério da Educação e Cultura. Proposta curricular - $2^{\circ}$ segmento da educação para jovens e adultos. Ensino fundamental. Brasília: MEC, 2002.

BRASIL. Conselho Nacional da Educação. Parecer $\mathrm{n}^{\circ}$ 11, de 10 de maio de 2000. Diretrizes Curriculares Nacionais para Educação de Jovens e Adultos: Câmara de educação Básica, Brasília, DF 2000.

BRASIL. Ministério da Educação. Conselho Nacional da Educação. Resolução no ${ }^{\circ}$, de maio de 2006. Diário Oficial da União. Brasília, DF ano 2006.

FREIRE, P. Pedagogia da autonomia: saberes necessários a pratica educativa. São Paulo: Paz e Terra, 1996.

FONSECA, Maria da Conceição F. R. Educação matemática na educação de jovens e adultos: especificidades, desafios e contribuições. Belo Horizonte: Autêntica, 2002.

HADDAD. S. \& DI PIERRO M. C. de. Escolarização de jovens e adultos. Revista Brasileira de Educação: ANPED. São Paulo, 2000.

LUDKE, M. \& ANDRÉ, M. E. D. A. Pesquisa em educação: abordagens qualitativas. São Paulo: EPU, 1996.

MARCONI, M. \& LAKATOS, E. M. Fundamentos de metodologia científica. SP: Atlas, 2009.

OLIVEIRA, M. K. de. Jovens e Adultos como sujeitos de conhecimento e aprendizagem. In: Revista Brasileira de Educação: São Paulo, 1999.

PAIVA, Vanilda Pereira. Educação popular e educação de jovens e adultos. Rio de Janeiro: Edições Loyola, 1973

PEREIRA, D. de F. F. Educação de jovens e adultos e educação popular: um olhar histórico sobre as políticas públicas ou a ausência delas. Ecos Revista Científica. São Paulo, v. 9, n. 1, p. 53-74, jan./jun. 2007.

RICHARDSON, R. J. Pesquisa Social: Métodos e Técnicas. São Paulo: Atlas, 1999.

ROMANELLI. O. de O. História da Educação no Brasil: Petrópolis: Vozes,1978.

SOARES, Leôncio José Gomes. Aprendendo com a diferença - estudos e pesquisas em educação de jovens e adultos. Belo Horizonte: Autêntica, 2006. 